Chemistry in

Medicine and

\title{
Chemically Induced Dimerization
}

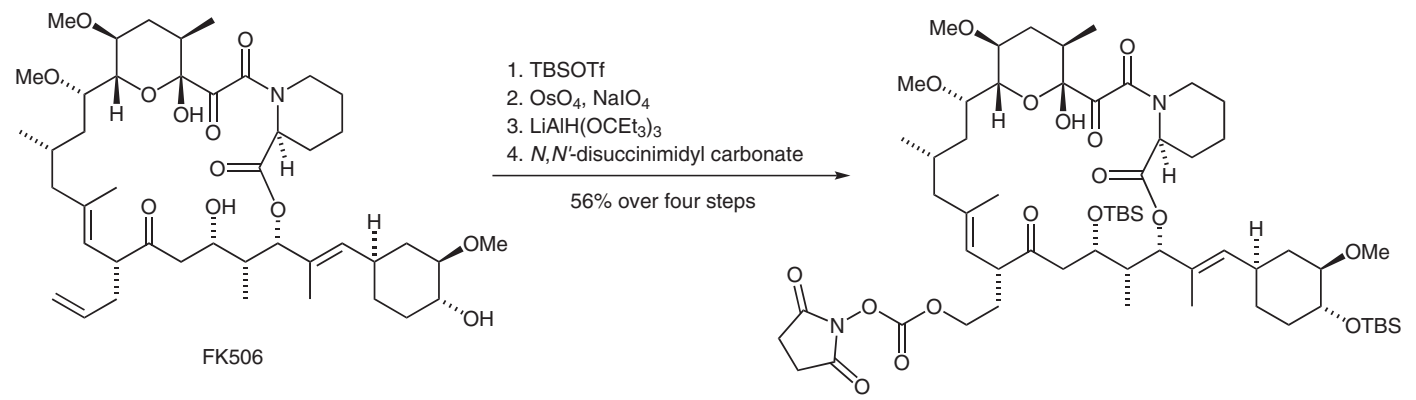

FK506 natural product

cellular signaling

transduction

immunophilin

FKBP proteins

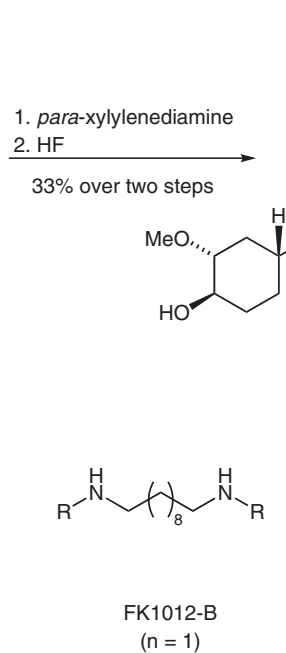

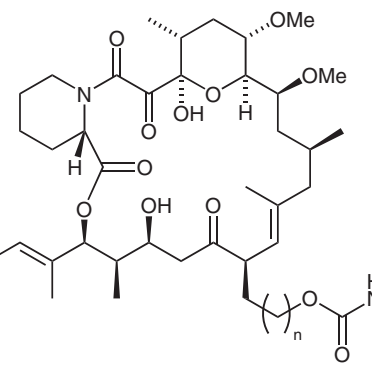<smiles>CCNCc1ccc(CNC(=O)OOC(C)C)cc1</smiles>
$\mathrm{R}=$ FK1012-A

Significance: Chemically induced dimerization (CID) is a powerful method in chemical biology that utilizes small-molecule chemical ligands to induce the dimerization (or oligomerization) of proteins and thus modulate their function in cells. It can be used to manipulate cellular regulatory pathways ranging from signal transduction to transcription. One of the first CID systems was developed by the laboratories of Schreiber and Crabtree in 1993.
Comment: The researchers synthesized homodimeric derivatives of the natural product FK506, FK1012s, which bind to the immunophilin FKBP. These ligands were used to dimerize and activate signaling proteins that were fused to FKBP. The monomeric form of the ligand (FK506-M), in contrast, blocked the signaling pathway. 